\title{
Avilés, por una convivencia intercultural. Proceso y resultados del Plan de Erradicación del chabolismo e integración social de los gitanos en Avilés 1989 - 2011
}

\section{Begoña Gutiérrez Álvarez *}

\section{Resumen}

En los años sesenta el municipio de Avilés experimenta un gran crecimiento demográfico que conlleva una importante segregación socio espacial de la población. La comunidad gitana (más de 500 personas) se asentó en espacios periféricos degradados, surgiendo siete asentamientos chabolistas. A finales de los años ochenta se diseña el Plan de Integración de Minorías Étnicas, donde se enmarca el Plan de Erradicación del Chabolismo. Entre 1989 y 2000 se construyen barrios de tipología especial o ciudades promocionales alejadas del centro urbano.

En la segunda etapa, se apuesta por el realojo de los gitanos chabolistas y habitantes de ciudades promocionales en viviendas normalizadas distribuidas en el entramado urbano, valorando que los procesos de realojo concentrados en un mismo enclave no facilitan la convivencia intercultural ni la incorporación social de los colectivos minoritarios.

Resultados del plan son el acceso a vivienda con alquileres protegidos y el acompañamiento social de 121 familias, mediante trabajo en red de entidades públicas y privada; , participación de las asociaciones gitanas y familias afectadas; implicación de diversas administraciones en la financiación y ejecución del plan ; así como el consenso político y social.

\section{Palabras clave}

Producción social de hábitat; Gestión social del hábitat; Participación ciudadana; Transformación social; Gitanos

\section{Abstract: Avilés, for intercultural coexistence. Process and results of the Plan for the Eradication of slums and social integration of Roma in Avilés 1989 - 2011}

In the sixties, the town of Aviles experienced high population growth which led to a major socio-spatial segregation of the population. The 1 Roma community (over 500 people) settled in impoverished peripheral areas where seven slum settlements emerged.

In the late eighties, the Plan for Integration of Ethnic Minorities was designed, where the Slum Eradication Plan was outlined. Between 1989 and 2000, neighbourhoods of a special typology or promotional cities were built away from the city centre.

In a second stage, gypsy slum-dwellers and promotional city inhabitants were then relocated into standard housing in the urban fabric, appreciating that relocation processes concentrated in one single enclave neither facilitate intercultural coexistence nor provide social incorporation of minority groups.

Results of the plan include: access to housing with protected rents and social support of 121 families through a network of public and private entities; participation of gypsy associations and families affected; involvement of various administrations in the funding and implementation of the plan; as well as political and social consensus.

\section{Key words}

Social Production of Habitat; Social Management of Habitat; Citizen Participation; Social Transformation; Roma communit

Recibido: 07/02/2012; aceptado definitivamente: 01/08/2011

* Trabajadora Social. Responsable del Programa de Incorporación Social en el Centro de Servicios Sociales del Ayuntamiento de Avilés C/ Galiana, 1133402 Avilés - Asturias E-mail: bgutierrez@ayto-aviles.es 


\section{Introducción}

Avilés, municipio costero al norte de Asturias, con una extensión de $25 \mathrm{~km} 2$ y una población actual de 84.202 (Fuente: Padrón Municipal de habitantes del Ayuntamiento de Avilés a 31 de diciembre de 2010.) habitantes, pasa de ser la cabecera de una comarca agrícola y ganadera en 1950 con unos 21.000 habitantes, a convertirse en los años sesenta en una ciudad de carácter siderúrgicoindustrial con un importante crecimiento económico generador de un fuerte movimiento migratorio no planificado, que trae consigo la proliferación de una urbanización especulativa con la consiguiente segregación socio espacial de la población.

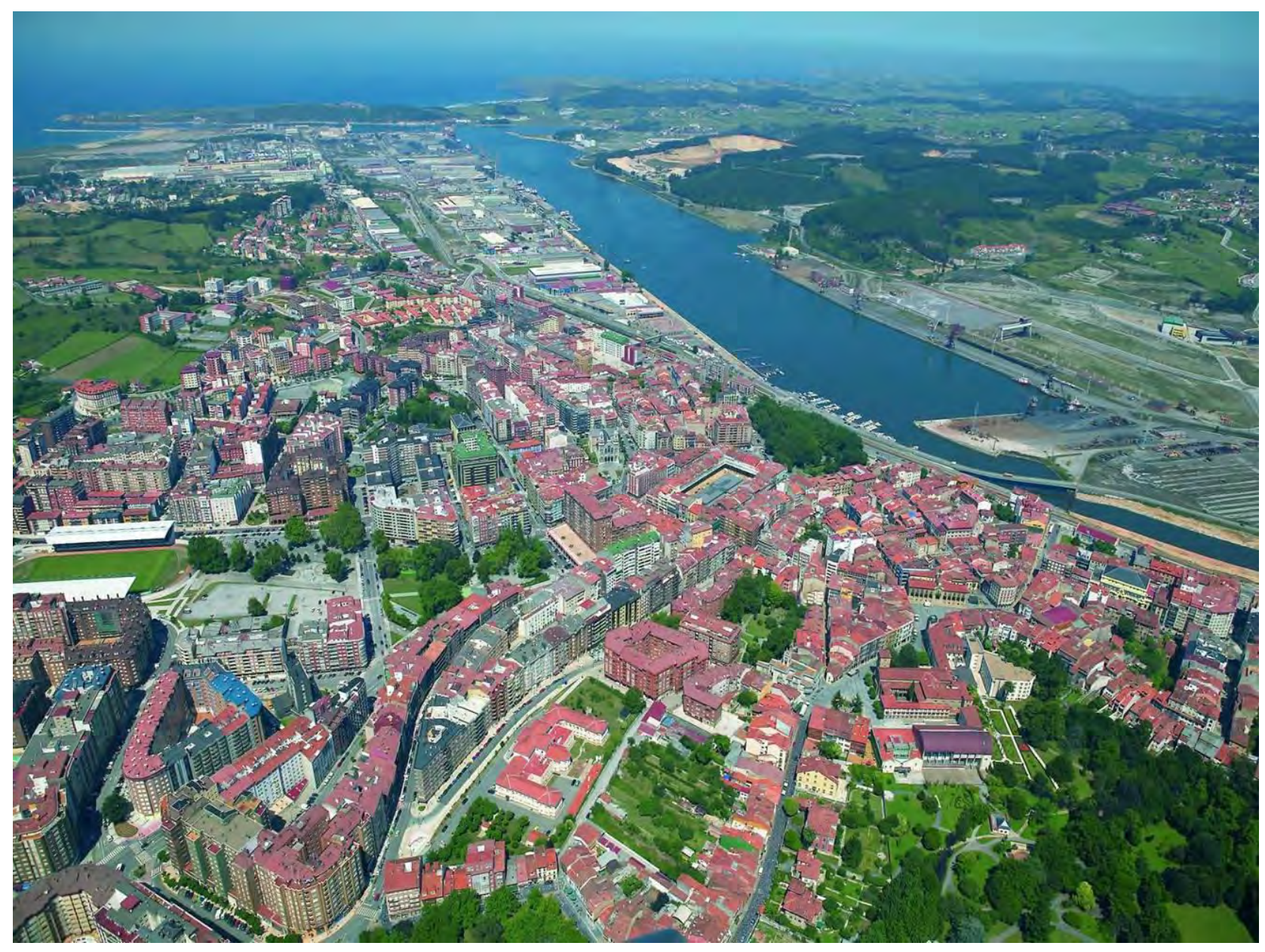

Figura 1. Vista aérea de la ciudad de Avilés.

Los años cincuenta y sesenta supusieron también un movimiento migratorio importante para la población gitana. Estas migraciones se darían tanto en el seno de la región como desde otras partes de España.

Los gitanos asturianos que históricamente se dedicaban a la compraventa de ganado, labores de temporerismo, cestería y otras actividades de subsistencia, se van asentando en zonas de la región en vías de desarrollo; la zona urbana central cuyos ejes son Oviedo, Gijón y Avilés, y las cuencas del Nalón y Caudal. A ellos se suman otras familias gitanas procedentes, preferentemente, de zonas limítrofes como León, A Coruña, Cantabria y País

Vasco. Los gitanos se asentaron en los márgenes de la emergente ciudad, construyendo chabolas y agrupándose en poblados de diferentes zonas, al lado de las barriadas de nueva creación, en espacios periféricos ambientalmente degradados, próximos a vías de comunicación y urbanísticamente abandonados (cfr. Agulló, 2004, p. 31) 


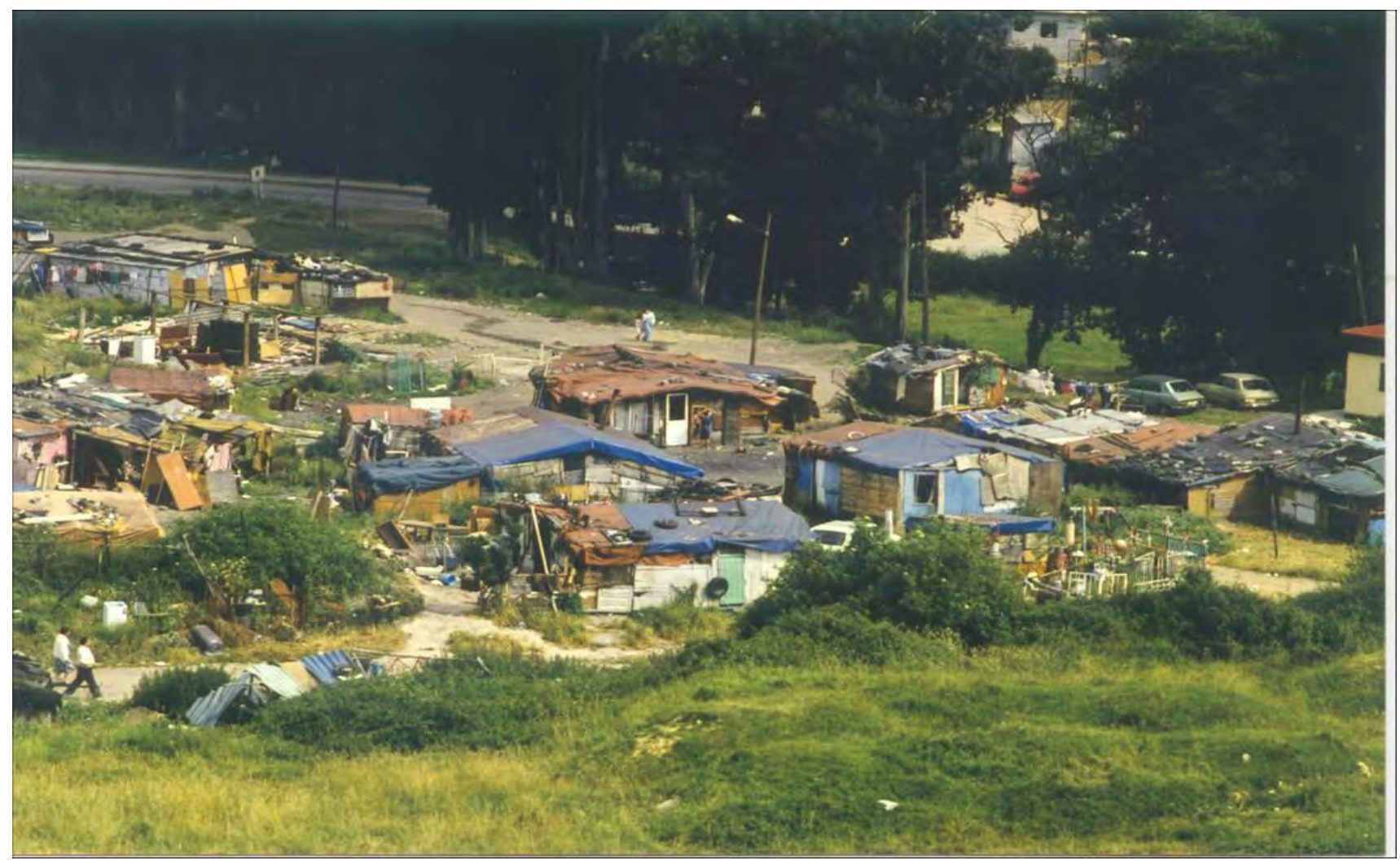

Figura 2. Asentamiento chabolista de Villalegre. Años 90.

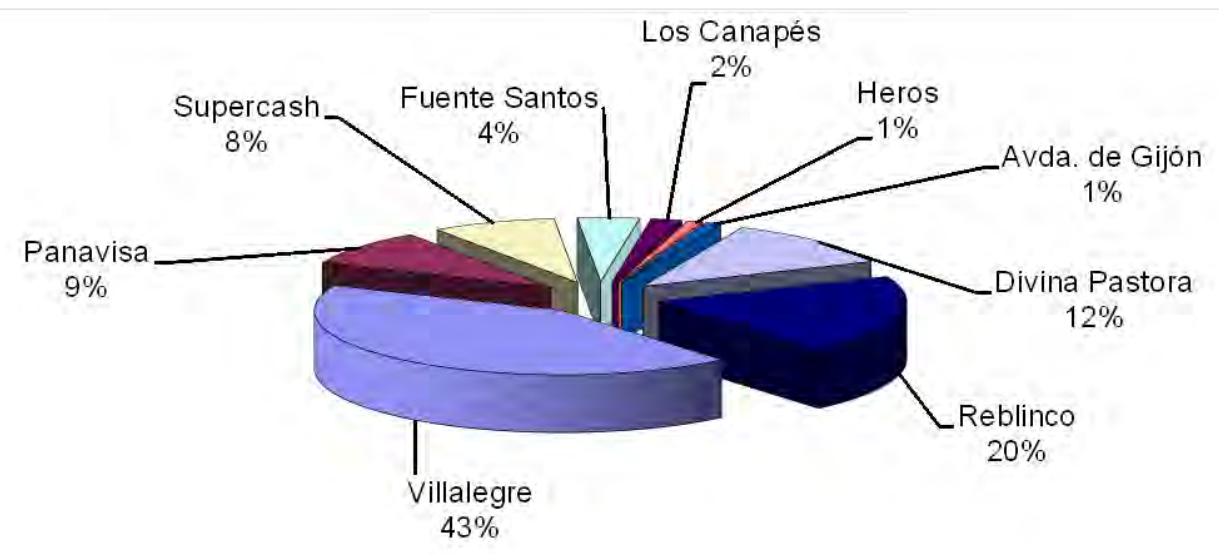

Figura 3. Poblados chabolista en Avilés en 1989. Fuente: Censo Servicios Sociales.

Los principales asentamientos eran: Villalegre-La Luz, Fuente Santos, Divina Pastora (población de procedencia portuguesa), Reblinco, Supercash, Panavisa y Gaxín, llegando a residir en ellos 578 personas (121 familias ${ }^{1}$ ) en ínfimas condiciones

${ }^{1}$ Estas son las familias incluidas en el Censo de chabolistas, lo que suponía el derecho a realojo. El Censo fue elaborado de higiene y salubridad, con graves dificultades de acceso a los recursos (vivienda, educación, sanidad, empleo, etc.) y carentes de movimientos asociativos propios.

por los Servicios Sociales municipales y la Policía Local. 


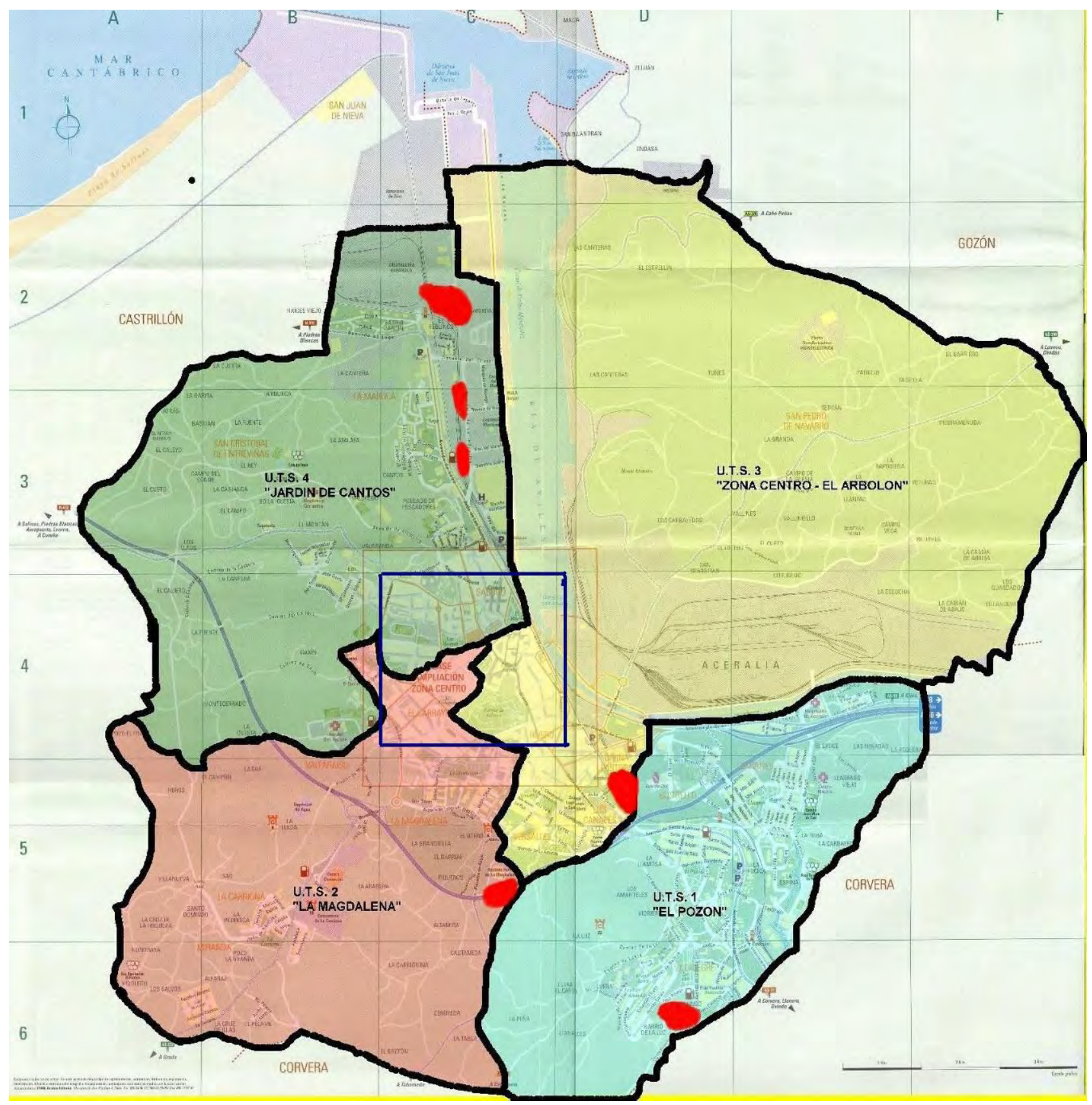

Figura 4. Principales poblados chabolista en Avilés en 1989. Fuente: Censo Servicios Sociales. Señalado en azul el casco histórico de la ciudad.

En los años 70 comienza la crisis económica y en los 80 la reconversión industrial, siendo en estos años la erradicación del chabolismo y la integración de la comunidad gitana una preocupación política y social cada vez mayor.

En este contexto se van estableciendo prioridades y realizando actuaciones, para seguir avanzando en:

- La cohesión social y convivencia vecinal.

- La desmitificación de estereotipos.
- El fomento del respeto y de la tolerancia.

- El conocimiento y enriquecimiento mutuo entre las minorías étnicas y la sociedad mayoritaria.

En definitiva, en conseguir una mayor convivencia y una ciudad inclusiva.

Para que se complete el proceso de inclusión social no es suficiente con suprimir el problema de la vivienda, sino que esta actuación debe ir acompañada de otras medidas en los campos de la educación y el trabajo, así como en la participación social y la sanidad. 
Por tanto, se deben ofrecer alternativas laborales de contrastado funcionamiento, como puede ser la regularización y normalización de algunas de sus actividades más frecuentes, inmersas la mayoría en la economía sumergida, para conseguir una paulatina incorporación al mercado de trabajo. Al mismo tiempo, ha de potenciarse la formación para facilitar el aprendizaje de diferentes oficios por parte de los colectivos gitanos marginados. Todo ello se debe hacer sin dejar de cuidar la educación escolar, que deberá centrarse en medidas como aumentar el apoyo a los escolares menores de 14 años (la edad a la que suelen abandonar los estudios, especialmente las niñas), para que continúen estudiando o, en su defecto, se formen en algún oficio concreto.

En este curso 2010-2011 hay en los centros educativos de Avilés 385 escolares de etnia gitana, 56 de los cuales se encuentran escolarizados en Institutos de Enseñanza Secundaria. Constan en la base de datos del Área de Bienestar Social, GUIAS ${ }^{2}$, compartida por diferentes servicios del Área, como Mujer, Formación y Empleo, Promoción Empresarial y Servicios Sociales, 105 niños y niñas gitanos en edad de escolarización en ESO. Pero, además de realojar a las familias y ocuparse del resto de áreas afines, es necesario realizar un seguimiento que nos permita valorar su situación, corregirla si fuera preciso, y aprender tanto de los aspectos positivos como de los negativos para futuras acciones, ya que, en contra de lo que a veces ocurre, la responsabilidad de la Administración Pública no debe terminar una vez efectuado el realojo. Porque la falta de actuación sostenida genera nuevos problemas que, como dice Rodríguez (2002), "en ocasiones, suponen un retroceso sobre los logros alcanzados años atrás para muchas familias". Así, el propio autor expone algunos de estos problemas:

2 Gestión Unificada de la Información para la Acción Sociolaboral.
- La concentración de población gitana (y de otros grupos vulnerables) en determinados barrios.

- El deterioro que están sufriendo las viviendas y el entorno de estos barrios.

- El hacinamiento que habitualmente se produce en este tipo de viviendas.

- La falta de garantías para el acceso a la vivienda pública y al mercado de la vivienda libre o en régimen de alquiler.

Para evitar estos y otros problemas deben llevarse a cabo programaciones integradas y continuadas en el tiempo con sus respectivos seguimientos; tal y como afirma Tapada (2002) "(...) sólo haciendo seguimientos precisos de los casos y comunicando cada uno de los aciertos y fracasos seremos capaces de diseñar para mejorar la calidad de vida de la comunidad gitana pensando en sus necesidades reales".

En definitiva, todas estas actuaciones habrán de hacerse sin olvidar quiénes son los verdaderos protagonistas; en este sentido, Rodríguez i Burch (1999) ofrece una recomendación general para el replanteamiento del trabajo social con gitanos en el tema de vivienda, que termina recordándonos esta situación fundamental:

"Hay que considerar la preparación de los profesionales para que la intervención final se sustente en unas prácticas pedagógicas que tiendan a concienciar a los gitanos de las alternativas de mejora de su realidad particular en un contexto de fricción intercultural y social y haciéndolo a partir de cómo lo sienten y viven los propios gitanos afectados convirtiéndolos de este modo en protagonistas".

En cuanto a las características y condiciones de las viviendas de realojo manejadas por el Programa de Erradicación del Chabolismo en Avilés $(\mathrm{PECH})$ son las siguientes:

1. El realojo habrá de hacerse en todas las zonas de la ciudad donde resida población no gitana. Este primer punto es importante porque supo- 
ne un problema a tener muy en cuenta; después de la experiencia de Ciudad Promocional ${ }^{3}$, tanto en Avilés como en otros lugares (Madrid, Gijón) donde ya habían demostrado su fracaso, convirtiéndose en guetos:

"Se llegó al convencimiento de que lo mejor era comprar viviendas y meter directamente en ellas a las familias e, incluso, en viviendas dentro de la zona urbana, evitando que fueran pisos muy altos" (Miguel Iglesias, 1997. Presidente de la Constructora Benéfica San Martín en la primera etapa del PECH).

$Y$ es que parece existir consenso en cuanto a que realojar a un colectivo como el de los gitanos requiere de una política de integración, pues la segregación espacial "fija, objetiva y perpetúa la imposibilidad de la integración", de tal modo que, en definitiva, lo que se hace es "colocarlos en su sitio, fuera, en la periferia" (Martínez Veiga, 2000). Además, hay que tener en cuenta que ubicar viviendas en barrios desfavorecidos puede reforzar, e incluso propiciar, determinadas situaciones de exclusión.

2. Ha de cuidarse que no se concentren muchas familias en la misma calle, para evitar conflictos vecinales y para garantizar que la adaptación de la familia ex chabolista al nuevo hábitat no se vea influida de manera negativa por sus pares ${ }^{4}$.

Uno de los problemas que acarrea la acumulación de realojos en una misma zona, aparte de los posibles conflictos de convivencia, que, por otra parte, en el caso del PECH han resultado ser menores de lo que en un principio se había pensado, es la pérdida de valor económico de esa zona; los pisos se desvalorizan

\footnotetext{
3 Las Ciudades Promocionales suelen consistir en un conjunto de viviendas situadas en un lugar apartado, en la periferia de la ciudad, donde se realoja exclusivamente a familias chabolistas.

"En la primera etapa buscábamos viviendas preferentemente unifamiliares con un terreno vinculado, en zonas periféricas, no en el centro de la ciudad, con el fin de atender características específicas de los destinatarios de las viviendas" (Iglesias, 1997).
}

en cuanto vive en el entorno alguna familia "problemática". Como hemos venido insistiendo, no hay que olvidar que los prejuicios sobre los gitanos siguen existiendo y que continúan produciéndose actitudes de rechazo hacia ellos.

3. En cuanto a la altura de los pisos, el PECH aboga por la adquisición de las plantas más bajas de los edificios, dadas las características y preferencias de los futuros inquilinos.

4. Deben ser accesibles los recursos sanitarios, educativos, formativos, sociales, etc.

La vivienda, tal y como señala Cortés, es un espacio a través del cual establecemos nuestra vida y referencias sociales, además de un lugar de actividad y relación social.

\section{Objetivo general del Programa de erradicación del chabolismo}

Erradicación del Chabolismo en Avilés, mediante el acceso a viviendas normalizadas con medidas de apoyo a la inserción sociolaboral de la población gitana y fomento de la convivencia intercultural.

\section{Objetivos por áreas}

- Vivienda: Acceso a una vivienda digna que facilite la convivencia y la incorporación social; renovación del entorno urbano que ocupaban los asentamientos erradicados.

- Salud: Fomento de hábitos que mejoran la calidad de vida.

- Formación y empleo: Mejorar las condiciones personales y sociales de empleabilidad del colectivo gitano.

- Educación: Sensibilizar de la importancia de la educación reglada como derecho e instrumento igualitario para la incorporación social y escolarización de todos los menores y normalización educativa del alumnado gitano. 


\section{Fechas clave}

\section{Año 1989: Inicio del Plan de Integración de Minorías Étnicas y primer Plan de Erradicación del Chabolismo}

De esta forma, se pone en marcha, a nivel local, y bajo los principios antes expuestos, el Plan de Integración de Minorías Étnicas (PIME), que se inicia en 1989, definiendo diversas actuaciones en las áreas de escolarización, documentación, sanidad e inserción laboral del pueblo gitano asentado en Avilés.

El Programa de Erradicación del Chabolismo ejecutado por el Ayuntamiento de Avilés se enmarca dentro del PIME, insistiendo en el área de vivienda y en 1999, con la aprobación y puesta en marcha del Programa para la Erradicación de la Pobreza en el municipio, se refuerza económicamente y con recursos humanos. Este programa pretende, dentro de un ámbito territorial, contando con el resto de actuaciones en el terreno de la integración de minorías étnicas y con una dimensión integradora, abordar las nuevas situaciones que provocaban el aumento de los realojos durante la segunda fase del PECH; en concreto, la adaptación al uso de la vivienda normalizada.

\section{Año 1993: Convenio de colaboración con la Constructora Benéfica San Martín, para el realojo de familias chabolistas del municipio}

La Constructora Benéfica San Martín (CBSM) fue fundada en 1968, por Tomás Méndez Trabanco, con el fin de facilitar una vivienda a aquellas familias sin recursos para acceder a una por sus propios medios. La entidad se denominó constructora, aunque se regía por unos estatutos basados en la ley de Asociaciones de 1964. Para conseguir su objetivo compraba viviendas o construía por su cuenta nuevas edificaciones. El contrato de adquisición era diferente al que funciona en la actualidad; en aquella primera etapa de la Cons- tructora, los beneficiarios pagaban una pequeña cantidad de entrada; después, se establecían unas cuotas de amortización muy bajas, de tal manera que la familia tenía acceso a la propiedad de la vivienda. Todavía perviven algunas de esas familias beneficiadas por este sistema, denominado "acceso difícil de la propiedad".

Después del convenio firmado con el Ayuntamiento de Avilés (1992), la fórmula descrita se cambió por la del alquiler; como explica el presidente de la entidad desde 1992, Miguel Ángel Iglesias Fernández, esto fue así por dos motivos:

"Uno, estar siempre al día, porque no estás esperando a la amortización para después hacer la escritura y hacer la transferencia de la propiedad al adquiriente; y, por otra parte, si cambiaban las circunstancias económicas o reales de la familia beneficiaria, nosotros recuperábamos la casa"

La Constructora pasaba a ser, a través del convenio de colaboración, un instrumento coordinado y financiado por el Ayuntamiento para la erradicación del chabolismo en el municipio.

En las etapas en que participó directamente la Consejería de Vivienda ${ }^{6}$ lo hizo para financiar reparaciones de las casas adquiridas por la CBSM, si bien en los últimos años esta financiación siempre se ha hecho a través del Ayuntamiento, aunque éste percibiera alguna subvención vía Principado de Asturias.

A la hora de examinar la vivienda existía una Comisión compuesta por un arquitecto municipal, un trabajador/a social y un representante de la CBSM. El arquitecto elaboraba un informe en el que se detallaban las necesidades del piso o de la casa (pintar, arreglar el suelo o reforzar las ventanas eran algunas de las reparaciones más usuales) (cfr. Agulló, 2004, p. 85-86). Actualmente, hay un trato más directo con los inquilinos,

\footnotetext{
5 Miguel Ángel Iglesias fue último Presidente de la Constructora Benéfica San Martín, ahora convertida en Fundación y presidida por la alcaldesa.

${ }^{6}$ Actualmente Consejería de Bienestar Social y Vivienda.
} 
pues son ellos mismos los que suelen acudir directamente a la Fundación cuando detectan algún problema en sus viviendas, encargándose ésta de arreglar los desperfectos y realizando una visita anual, como mínimo, de inspección.

Desde la firma del convenio con el Ayuntamiento hasta que se pone en marcha el nuevo Programa de Erradicación (2000-2003), la fórmula financiera era la siguiente: el Ayuntamiento establecía un presupuesto determinado en cada ejercicio para la compra de viviendas, y al Principado se le solicitaba alguna subvención para reparaciones en las viviendas. De esta forma, se combinaba la compra de viviendas prácticamente habitables con la adquisición de aquellas que requerían arreglos importantes.

Con el nuevo Programa se consiguió una mayor implicación del Principado de Asturias en la financiación del proyecto, al firmar un convenio específico de colaboración para este fin: adquisición de viviendas para el realojo de familias chabolistas de Avilés.

Respecto al proceso de compra y adjudicación de las viviendas, la Constructora es quien localiza las viviendas, para después consultar con los Servicios Sociales la idoneidad de su adquisición con respecto a los criterios de realojo del PECH (tales como que no se acumulen más de dos familias por edificio, por ejemplo). Una vez estudiada cada situación, se decide si se compra o no la vivienda. En caso de que se dé el visto bueno a la operación, la Constructora adquiere la vivienda, reparándola si fuera necesario; a continuación se valora qué familia de entre las censadas como chabolistas o residentes en Ciudad Promocional resulta ser la idónea para la vivienda adquirida. Entonces se le notifica a la familia beneficiaria, que, junto con el educador o la educadora de su Centro de Servicios Sociales, habrá de acudir a firmar el contrato de alquiler con la CBSM, la cual en coordinación con Servicios Sociales fija un alquiler adaptado a la situación sociofamiliar. Si durante el seguimiento del realojo, que se mantiene un mínimo de seis meses, surge algún problema o dificultad con los inquilinos, la coordinación entre la entidad y los Servicios Municipales, junto con los inquilinos, tratan de resolverlo de la mejor manera posible.

\section{Año 1997}

Se implica el Principado de Asturias con la construcción de la Ciudad Promocional de Valliniello, destinada al realojo temporal -tres años como periodo máximo, si bien hay familias que han estado diez años- de 36 familias. Estas viviendas se construyen en un enclave aislado, con graves deficiencias de acceso e infraestructuras, donde no se comparten espacios con personas de distinto origen. Todo ello supone fuertes resistencias por parte de la población que residía en la zona y dificulta la integración social de los realojados.

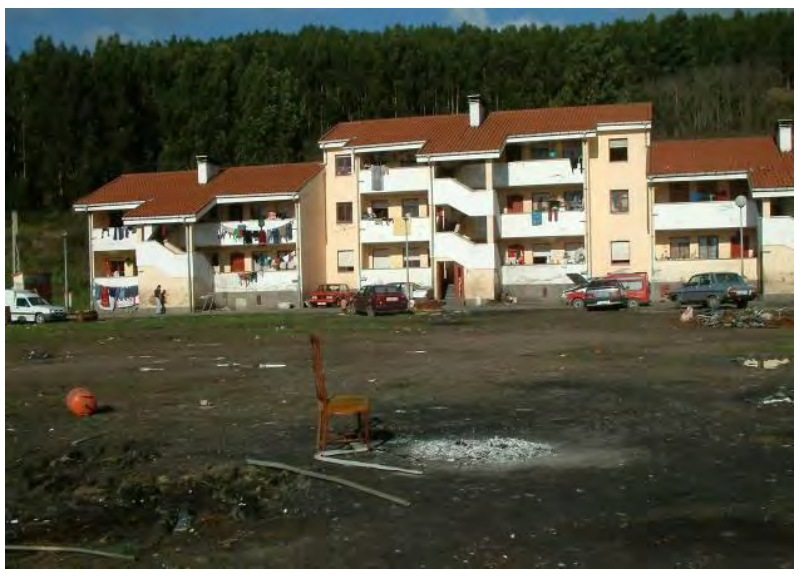

Figura 5. Ciudad Promocional de Valliniello. Año 2006.

\section{Año 2000}

- Segundo Plan de Erradicación del Chabolismo (PECH en adelante), en el que se renuncia expresamente al modelo de Ciudad Promocional en favor de la integración en viviendas normalizadas dentro del entramado urbano.

- Convenio Ayuntamiento de Avilés-Fundación Secretariado Gitano, para apoyar la intervención social con las familias realojadas, y eje- 
cución del Proyecto "Acceder", dirigido a la orientación e inserción laboral del colectivo gitano.

- Constitución, dentro del Consejo Municipal de Bienestar Social, del Grupo de Trabajo de Minorías Étnicas, compuesto por técnicos, políticos, entidades sociales y asociaciones gitanas. El grupo determina 28 iniciativas en las áreas de vivienda, educación, salud y empleo.

- Erradicación asentamiento chabolista de Villalegre.

\section{Año 2001}

- Convenio Ayuntamiento de Avilés-Principado de Asturias para la Erradicación del Chabolismo.

\section{Año 2002}

- Erradicación de los asentamientos chabolistas de Divina Pastora y Fuente Santos.

- Convenio Ayuntamiento de AvilésUniversidad de Oviedo para el desarrollo de la investigación "Erradicación del Chabolismo e integración social de los gitanos en Avilés.

\section{Año 2003}

- Erradicación de los asentamientos chabolistas de Supercash y Gaxín.

- La Ley 1/2003 de Servicios Sociales del Principado de Asturias, de 24 de febrero, marca el principio de una nueva estrategia contra la exclusión social en la región.

\section{Año 2004}

- Nuevo Convenio entre el Ayuntamiento de Avilés y el Principado de Asturias (20042006).

- Nuevo Convenio entre el Ayuntamiento de Avilés y la Fundación San Martín, antes entidad benéfica y ahora municipal. (2004-2006).

- Convenio Principado-Ayuntamiento Avilés-
Fundación San Martín para el desarrollo del Programa Experimental de Acceso a la vivienda de Alquiler para la Minoría étnica gitana.

- Erradicación de los asentamientos chabolistas de Panavisa y Reblinco.

Desde 2001 la Constructora comenzó a gestionar el cambio de personalidad jurídica, hasta que se constituye en Fundación, bajo el nombre de Fundación San Martín (FSM). Su objetivo sigue siendo el mismo: facilitar una vivienda digna a quien no dispone de medios necesarios para adquirirla. Pero esta nueva fórmula administrativa agilizará las gestiones y procedimientos. Otro beneficio de ser Fundación es que pasa a ser una entidad semipública, lo que significa que cuenta con mayores beneficios fiscales y que tiene la posibilidad de conseguir nuevas vías de financiación; se crea un Patronato compuesto por representantes de las diferentes administraciones, lo que supone la existencia de una partida destinada a la Fundación con cargo a los presupuestos municipales. De esta forma, la financiación no acarreará problemas de desconfianza, como ocurrió en el pasado (en la legislatura 96/99), cuando una auditoría paralizó durante meses la actuación de la Constructora como colaboradora dentro del Programa de Erradicación.

Una vez que desaparecen todas las chabolas del municipio avilesino, el nuevo fin de la Fundación San Martín es la erradicación de la infravivienda, así como la puesta en marcha de nuevas alternativas de acceso a la vivienda para los colectivos con mayores dificultades. La infravivienda se convierte a partir de la erradicación en uno de los objetivos determinantes para el logro de una vida digna del colectivo gitano. Los grupos de discusión reflejan la complejidad del asunto: la falta de un trabajo digno y los problemas (defectos, tamaño no adecuado, etc.) en la vivienda concedida son quejas que se repiten hasta la saciedad por parte de los propios gitanos. 


\section{Año 2007}

- Demolición de la Ciudad promocional de Valliniello, ejemplo de poblado de tipología especial. Se encontraba muy deteriorada, con sus ocupantes y con un entorno profundamuchas viviendas tapiadas tras el realojo de mente degradado. Se realoja a las familias que aún residían allí en vivienda normalizada.

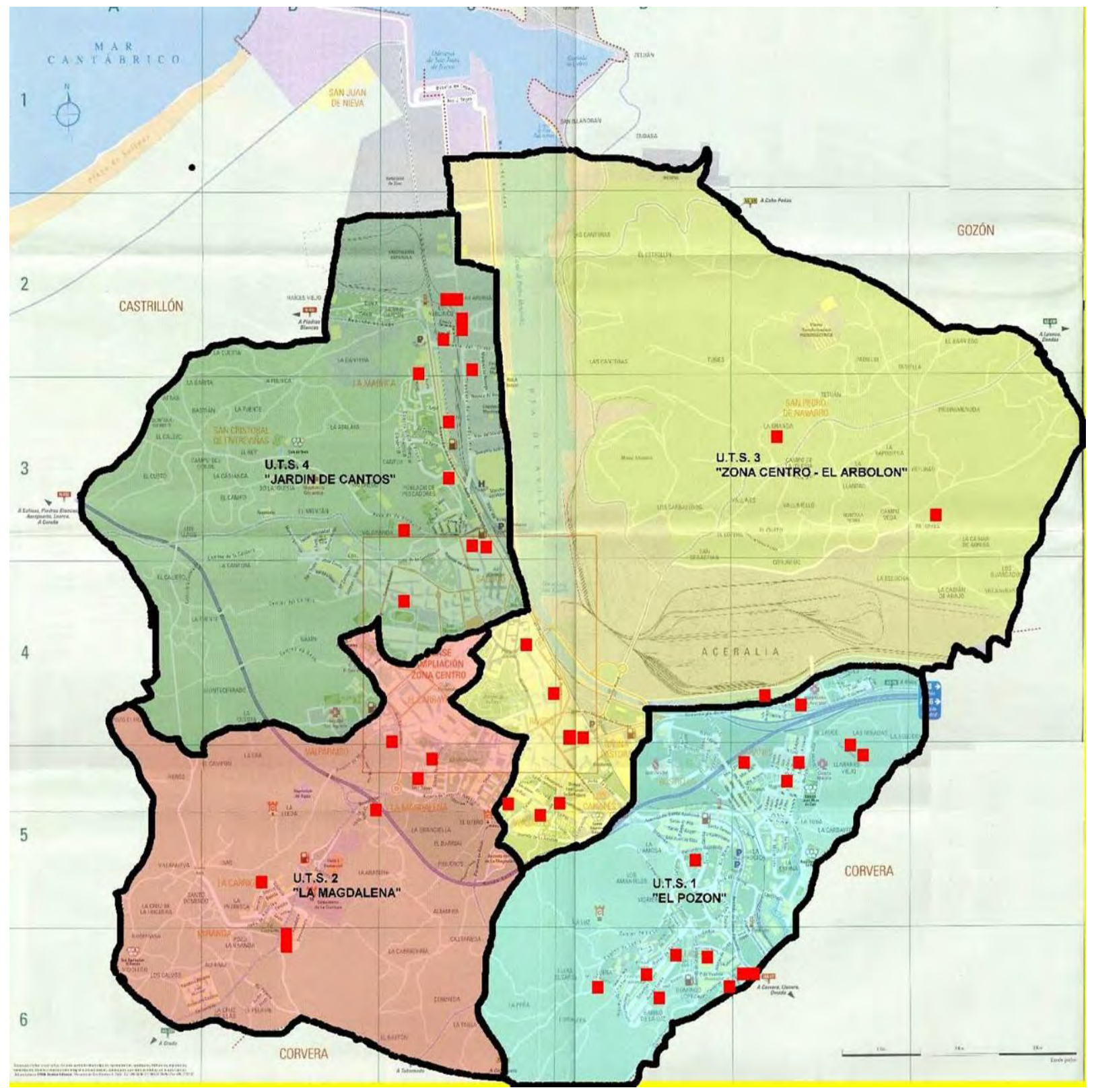

Figura 6. Distribución de las familias realojadas. Fuente: Servicios Sociales, 2007.

\section{Periodo 2007- 2010}

- Nuevo Convenio con dos líneas: a) Adquisición, Rehabilitación y Mantenimiento de Viviendas con el objetivo de erradicar la infravivienda (1.815.000 €); b) Intermediación en el mercado de alquiler con el objetivo de facilitar el acceso a la vivienda de los colectivos más vulnerables entre los que se encuentran los de etnia gitana $(720.000 €)$

Pasados ya unos años desde la desaparición de los asentamientos chabolistas y el derribo de la Ciudad Promocional, procede reflexionar sobre los aprendizajes y los errores cometidos y valorar una etapa de intenso trabajo en diferentes áreas que culminó con el derribo de la Ciudad Promocional en diciembre de 2007 una vez se realojó a 
todas las familias que allí residían en viviendas integradas en el entorno urbano.

\section{Área de vivienda}

No se ha instalado ningún nuevo asentamiento chabolista en la ciudad. La labor continuada de la Policía Local ante cualquier aviso de los Servicios Sociales o de cualquier otro servicio municipal, asociación o ciudadano/a ha permitido erradicar definitivamente el chabolismo.

Se mantiene así mismo el acompañamiento social de aquellas familias que lo precisan y se han buscado alternativas a través del Programa experimental de acceso a la vivienda de alquiler de la minoría étnica gitana, iniciado en el año 2004, para evitar situaciones de hacinamiento ante el crecimiento natural de las familias y las situaciones detectadas de infravivienda. En este programa colaboran la Fundación San Martín, mediando entre los propietarios particulares e inquilinos y evaluando anualmente el uso de las viviendas que tiene en propiedad así como de las alquiladas y el Principado de Asturias, que aporta la financiación. Treinta y cinco familias se han beneficiado de este apoyo.

En 2008 se reformula el programa, al que se han incorporado 39 nuevas familias que acceden al mismo, no ya por pertenencia a una etnia determinada, sino por constituir un sector de población en riesgo o situación de exclusión social.

\section{Área de formación y empleo}

Los equipos interdisciplinares de los Centros de Servicios Sociales se vieron reforzados con la presencia de técnicas de acompañamiento laboral pertenecientes al Servicio de Formación y Empleo en los cuatro centros durante dos días a la semana. Lógicamente no limitaban su función a la atención del colectivo gitano, pero su presencia en los centros y la coordinación tan estrecha que facilita el compartir espacio, redundó en una atención integral a colectivos con mayores dificul- tades para el acceso al empleo y la formación ocupacional, los cuales tenían dificultades para mantenerse en los recursos normalizados dispuestos para la población general.

Igualmente se mantiene el programa Acceder gestionado por la Fundación Secretariado Gitano. Destacar el desarrollo o entrada en vigor de normas que establecen derechos de carácter subjetivo y por tanto constituyen avances muy notables para hacer efectivo un sistema de servicios sociales de calidad, garantista y plenamente universal, en concreto a finales del año 2005 entra en vigor la Ley 4/2005 de Salario Social Básico del Principado de Asturias.

\section{Área de educación}

Desde el año 2006 se mantiene un Convenio de colaboración entre el Ayuntamiento de Avilés y Cruz Roja-Asamblea Comarcal de Avilés financiado por el Principado de Asturias en el marco de orientado a la alfabetización de adultos y que es mayoritariamente utilizado por mujeres gitanas. Se han desarrollado programas específicos de refuerzo escolar subvencionados por el Ayuntamiento para niñas y niños gitanos por parte de Cruz Roja y Fundación Secretariado Gitano y Escuelas Taller.

\section{Elementos determinantes del Plan}

- Trabajo en red de las diversas entidades públicas y privadas.

- Participación de asociaciones gitanas y familias afectadas.

- Implicación de diversas Administraciones en la financiación y ejecución del Plan.

- Consenso político: El Plan es aprobado en Diciembre del 2000 por unanimidad de todos los grupos políticos municipales (PSOE, PP, IU, URAS). Se mantiene la misma unanimidad con el cambio de gobierno en el 2003 (PSOE, IU, PP, ASIA).

- Consenso social: Fundación San Martín, 
Fundación Secretariado Gitano, Cruz Roja, Cáritas, Asociaciones gitanas (UNGA, La Quel de los Chaborros, Mulheres de la Divina Pastora), Representantes de Familias deCiudad Promocional de Valliniello y organizaciones sindicales.
- Apoyo técnico: Servicios Municipales de Educación, Formación y Empleo; Servicios Técnicos. Policía Local y Servicios Sociales. Mencionar el apoyo del Registro Civil en el proceso de documentar a la población afectada al inicio del Plan.

\begin{tabular}{|c|c|}
\hline $\begin{array}{l}\text { Partidos políticos con representación en el } \\
\text { Pleno Municipal, legislatura 1999-2003 }\end{array}$ & $\begin{array}{l}\text {-Grupo Socialista } \\
\text {-Grupo Popular } \\
\text {-Grupo de Izquierda Unida } \\
\text {-Representante de URAS }\end{array}$ \\
\hline Entidades Sociales colaboradoras & $\begin{array}{l}\text {-Cáritas Interparroquial de Avilés } \\
\text {-Asamblea Comarcal de Cruz Roja Española } \\
\text {-Fundación Secretariado General Gitano } \\
\text {-Asociación Sociocultural UNGA } \\
\text {-Constructora Benéfica San Martín }\end{array}$ \\
\hline Agrupaciones y representantes gitanos/as & $\begin{array}{l}\text {-La Quel de los Chaborrós } \\
\text {-Asociación Mulheres de Divina Pastora } \\
\text {-Familias Ciudad Promocional }\end{array}$ \\
\hline Sindicatos & $\begin{array}{l}\text {-Unión General de Trabajadores } \\
\text {-Unión Comarcal de Comisiones Obreras }\end{array}$ \\
\hline Servicios Municipales & $\begin{array}{l}\text {-Servicio de Desarrollo Local y Empleo } \\
\text {-Servicio de Educación } \\
\text {-Servicios Sociales }\end{array}$ \\
\hline
\end{tabular}

Figura 7. Entidades integrantes del Grupo de Trabajo de Minorías Étnicas. Fuente: Centro Municipal de Servicios Sociales, Ayuntamiento de Avilés

La voluntad política ha sido un factor determinante a la hora de atajar el chabolismo. Se puede hablar de la existencia de varias sensibilidades en el ámbito político; no siempre fue un programa apoyado ni entendido por todos. No será hasta la redacción del nuevo Programa de Erradicación, aprobado en 2000, cuando esa voluntad se vea reflejada en una inyección económica que dará un giro importante a la erradicación y los realojos. El nuevo impulso queda plasmado en la formación del Grupo de Trabajo sobre Minorías Étnicas, compuesto por todos los grupos políticos con representación en el pleno del Ayuntamiento (PSOE, PP, IU y URAS), y por organizaciones de índole social implicadas de una u otra forma con la integración de la población gitana (Cáritas, Cruz Roja, FSGG y UNGA); el grupo también cuenta con la participación de miembros del co- lectivo gitano.

El refuerzo económico se materializa mediante el convenio firmado entre el Ayuntamiento de Avilés y la Consejería de Bienestar Social y Vivienda (entonces de Infraestructuras y Política Territorial), por el que se financia la inversión en compra y rehabilitación de viviendas.

No podemos desdeñar, por otra parte, los esfuerzos realizados por el personal de Servicios Sociales desde el principio del programa en el año 1989. De hecho, pensamos que una política con unos objetivos tan ambiciosos, como es la inserción de un número importante de personas (la mayoría compuesta por menores de edad) que vivían en situación de exclusión, merece un tiempo de adaptación y aclimatación al propio devenir de los cambios proyectados. 


\section{Financiación}

- Ayuntamiento de Avilés.

- Principado de Asturias.
- Administración Central (Vivienda y Políticas Sociales).

- Aportaciones puntuales de entidades financieras (La Caixa y Cajastur).

\begin{tabular}{|c|c|c|c|}
\hline & Coste Total & Ayto. Avilés & Principado $^{1}$ \\
\hline I Plan 1989-99 & $3.409 .408 €$ & $1.235 .592 €$ & $2.173 .816 €$ \\
\hline II Plan 2000-06 & $4.901 .389 €$ & $2.701 .506 €$ & $2.199 .883 €$ \\
\hline $2007-2010$ & $2.535 .000 €$ & $914.848 €$ & $1.620 .152 €$ \\
\hline TOTAL & $10.845 .797 €$ & $4.851 .946 €(44,7 \%)$ & $5.993 .851 €(55,3 \%)$ \\
\hline
\end{tabular}

Figura 8. Coste del programa desde el año 1989 hasta el año 2010.

1- En la financiación del Principado van incluidas las aportaciones de la Administración Central

2- $1.234 .156 €(36,2 \%)$ fueron destinados a la construcción de la Ciudad Promocional.

3- Desde el año 2007 no hay Convenio para la Erradicación del Chabolismo. Se ha firmado un nuevo Convenio con el objeto de favorecer el acceso a la vivienda de los colectivos más vulnerables entre los que se encuentran los de etnia gitana.

\section{Recursos movilizados}

- Acuerdo municipal por el que se pone a disposición de las familias chabolistas el parque municipal de viviendas, hasta el momento a disposición exclusivamente de maestros y funcionarios.

- Apoyo de la Consejería de Trabajo y Promoción de Empleo financiando, a través del Pacto Institucional por el Empleo y en concreto, de la medida inserción laboral de colectivos desfavorecidos, la rehabilitación de 4 viviendas propiedad de la Fundación San Martín, y destinadas al realojo.

- El Plan Local de Inclusión, dirigido a favorecer la integración social y laboral de personas carentes de recursos, contempla entre sus programas formativo-laborales la capacitación y adquisición de habilidades laborales. En es- te sentido, el Ayuntamiento de Avilés y los principales agentes del territorio (sindicatos y Federación Asturiana de Empresarios con la colaboración del Gobierno del Principado de Asturias), consensúan en el documento marco del acuerdo Avilés Avanza. Hacia un territorio económica y socialmente responsable 2008-2011 que una de sus líneas prioritarias sea el acompañamiento a la incorporación socio laboral tutelada dirigidos a aquellas personas que, debido a unas especiales características y trayectoria vital, presentan dificultades par aprovechar las oportunidades del mercado laboral.

- Destacar el desarrollo del Programa Territorial de Empleo del Ayuntamiento de Avilés, en concreto la línea tercera de actuación, que consiste en una serie de medidas entre las que se incluyen ayudas a la creación de las Empresas de Inserción que desarrollen actividades en el territorio y la creación a finales del año 2008 de una Mesa de coordinación para la promoción de las Empresas de Inserción con apoyo técnico y financiero por parte del Área de Bienestar Social del Ayuntamiento.

- Publicación en el BOPA número 273 de 25 de noviembre de 2009 de la Instrucción para la incorporación de criterios sociales en los con- 
tratos públicos del Ayuntamiento de Avilés para la inserción sociolaboral de personas en situación de exclusión social y/o discapacitadas, promover la calidad en el empleo, favorecer la igualdad efectiva entre mujeres y hombres, o facilitar la seguridad y salud laboral.

- Colaboración de entidades como Cruz Roja, Cáritas, UNGA y Fundación Secretariado Gitano en los proyectos individualizados de intervención y de acompañamiento social de las familias realojadas.

- Introducción del criterio de realojo en las bases de selección de trabajadores del Plan Local de Empleo de Avilés.

- Control policial de nuevos asentamientos a través de la figura del controlador del chabolismo.

- Refuerzo de los recursos humanos y materiales de la Fundación San Martín.

- Proyecto socio-educativo "Mejorando nuestro Futuro / Estipeando Amaré Callicó", financiado por La Caixa.

- Creación de escuela de padres y madres en los dos colegios públicos de Avilés con mayor presencia de alumnado gitano y programas de refuerzo escolar en Ecuación Infantil y Primaria para todos los centros escolares interesados, con la colaboración de Cruz Roja y Fundación Secretariado Gitano.

\section{Resultados}

- Renuncia a la construcción de barrios de tipología especial

- Realojo con criterios de dispersión geográfica.

- 121 familias realojadas en viviendas dignas.

- Erradicación de 7 asentamientos chabolistas.

- Mayor interacción y convivencia entre personas payas y gitanas.

- Incremento progresivo de la "normalización" sanitaria, social y educativa.

- Promoción del movimiento asociativo específico, especialmente de jóvenes y mujeres.

- Apoyo a la normalización y continuidad en los procesos de acceso al mercado laboral de la Comunidad Gitana, a través de itinerarios individualizados de inserción.

- Mejora del entorno urbano donde se ubicaban los poblados chabolistas.

- Consecución progresiva de una intervención integral sobre la exclusión.

\section{Lecciones aprendidas}

\section{En cuanto a metodología de trabajo}

- La amplia participación y consenso social, junto con la implicación de las personas afectadas multiplica la eficacia de las actuaciones.

- El trabajo en red ha permitido la concurrencia en un territorio de diversos planes, programas y proyectos con objetivos y estrategias de intervención complementarias, facilitando una intervención integral.

- La implicación de distintas Administraciones en la planificación, evaluación y financiación ha facilitado la multidimensionalidad del proyecto.

\section{En cuanto a los contenidos del proyecto}

- La conveniencia de integrar los planes concretos de erradicación del chabolismo en programas más amplios de inclusión social que contemplen toda la complejidad de las situaciones.

- El realojo concentrado en un mismo enclave no facilita la convivencia intercultural ni la incorporación social de los colectivos minoritarios.

\section{Oportunidades de mejora}

- Fomentar entre la comunidad gitana, la necesidad de la formación como un valor añadido 
para su empleabilidad, estableciendo medidas para evitar el abandono escolar en el paso de educación primaria a secundaria.

- Cambio de actitudes entre el colectivo gitano, impulsando la corresponsabilidad en sus propios procesos de inclusión social.

- Mejorar las estrategias de incorporación laboral en empleos ordinarios, como mecanismo de integración social efectiva y de promoción de la autonomía personal.

\section{Transferibilidad del proyecto}

- En el año 2002 el PECH de Avilés obtiene la calificación de "Buena Práctica" a nivel Good para la mejora de los Asentamientos humanos", concedida por Naciones Unidas.

- Publicación del Estudio Erradicación del Chabolismo e Integración Social de los gitanos en Avilés. Investigación, evaluación y propuestas elaborado por la Universidad de Oviedo y el Ayuntamiento de Avilés.

- En 2006 Naciones Unidas destaca con el calificativo Best el plan de realojamiento e integración social de minorías étnicas en Avilés. Por segunda vez un jurado internacional otorga una distinción a este plan. El Comité Hábitat español nominó y remitió a Naciones Unidas un total de treinta y dos prácticas (una de ellas fue premiada y otras cinco destacadas como Best), que han competido con cerca de 700 propuestas de 88 países. Los premios los ha otorgado un Jurado internacional de cinco miembros presidido por el profesor de la Universidad de Washington Abdulkarim Banguri.

- Seleccionado como buena práctica por el III Plan Nacional para la Inclusión Social del Reino de España 2005-2006

- Avilés fue ciudad anfitriona del encuentro promovido por la Comisión Europea Peer Review meeting Social Inclusión o Evaluación
Paritaria para intercambio de experiencias y buenas prácticas, en este caso también relacionadas con minorías étnicas. En el encuentro participaron también representantes de Eslovaquia, Bulgaria, República Checa, Hungría, Portugal, Grecia, Eslovenia y España.

- Reconocimientos por parte de la Consejería de Bienestar Social y Vivienda del Principado de Asturias, de la Agencia de Derechos Fundamentales de la Unión Europea, de Cruz roja Española y del Colegio Oficial de Trabajo Social de Asturias.

- Seleccionado el PECH como una mejor práctica iberoamericana y del Caribe en el II Encuentro Iberoamericano de Mejores Prácticas Urbanas. ONU-HABITAT / Oficina Regional para América Latina y el Caribe.

\section{Situación actual}

\section{Renuncias a vivienda}

Doce, generalmente relacionadas con desacuerdos con la localización de la vivienda o conflictos. En un caso el arrendatario accedió a vivienda propia y en otro a vivienda social en el que era su antiguo barrio, ya que no es incompatible el ser beneficiario de vivienda de realojo municipal con las convocatorias de vivienda protegida.

\section{Renuncias previas al realojo}

Cinco, mayoritariamente relacionadas con desacuerdos en la ubicación de la vivienda.

\section{Desahucios}

Once, todos por impago. En un caso se fue a juicio ante las quejas masivas presentadas por Registro Municipal del barrio en el que residían, así como informes de los Servicios Sociales y de la Policía Local y Guardia Civil, pero la demanda fue desestimada por el Juzgado. Las familias no tienen opción a hacer una nueva chabola ya que cualquier asentamiento detectado es derruido previo aviso de la Policía Local. 


\section{Fallecimientos}

Tres.

\section{Seguimiento- acompañamiento social}

El seguimiento en cuanto a adaptación a la vivienda y al barrio se realiza durante un mínimo de seis meses, periodo a partir del cual se valora la necesidad de continuidad o el "alta".

\section{Quejas}

Se han recibido quejas de un $8 \%$ de las familias realojadas, en su mayoría por ruidos, nulo cuidado del entorno comunitario o molestias relacionadas con el gran número de visitas que reciben alguna de ellas.

\section{Importe del alquiler}

Adaptados a los ingresos de la unidad familiar (10\% de los mismos) y revisables en caso de modificarse la situación económica. La media de alquiler mensual es de $65 €$.

En Asturias existe una renta básica, el Salario Social, en principio no sujeta a contraprestación que oscila entre un mínimo de $442.96 €$ para una persona sola a un máximo de $767,42 €$ para familias de seis miembros o más en el año 2011.

\section{Miembros de la unidad familiar}

Media de 4,5 personas.

\section{¿Y ahora?}

- La Fundación San Martín gestiona, a enero de 2011, 162 viviendas: 102 en propiedad y 60 de mediación en el alquiler. Ha firmado Convenios con otros ayuntamientos de la Comarca en los que aún persisten asentamientos chabolistas.

- Actualmente se mantienen 73 familias en viviendas propiedad de la Fundación San Martín (340 personas), 1 en vivienda municipal y 12 en viviendas sociales propiedad de
VIPASA $^{7}$ (48 personas), en ambos casos con alquileres protegidos.

- 872 familias se beneficiaron en el 2010 del Salario Social Básico. De ellas 280 con proyecto personalizado de incorporación social.

- Articulación de proyectos locales por la inclusión en colaboración con el tejido asociativo.

- Apuesta por la educación como medio de cohesión social: Programa de Apertura de Centros Educativos a la Comunidad, Programa de prevención del absentismo escolar y Programa de Educación de Calle.

- Desarrollo ordenado y cohesionado del territorio (políticas activas de vivienda en colaboración con distintas administraciones: vivienda protegida, intermediación en el alquiler; ventanilla única de vivienda que aglutina los servicios de las tres administraciones).

\section{Referencias}

AGULLO, Esteban y CABO, Jorge et al. Erradicación del chabolismo e integración social de los gitanos en Avilés. Oviedo: Servicio de Publicaciones de la Universidad de Oviedo y Ayuntamiento de Avilés, 2004.

ARENAS, Miguel. Los gitanos de Avilés. Pervivencia cultural e integración social. Avilés: Ayuntamiento de Avilés (inédito), 1990.

CÁRITAS. Informe: Problemas de vivienda y exclusión social en Aragón. Zaragoza: Cáritas, 2001.

CES. La pobreza y la exclusión social en España. Madrid: CES, 1997.

Centro de Investigaciones Sociológicas. Tolerancia y aceptación social, Datos de Opinión, vol. 5, 1996. <http://www.cis. es/cis/opencms/Archivos/Boletines/05/BDO_5_tolerancia.html> (Consultado el 24 septiembre de 2012).

CORTÉS, Luis. Hablando sobre exclusión resi-

\footnotetext{
7 Viviendas del Principado de Asturias.
} 
dencial, en La Acción Social, cuadernos de formación, vol. 41. Madrid: Cáritas Española, 1997. CORTÉS, Luis y PANIAGUA, José León. La vivienda como factor de exclusión social, en Documentación Social. Revista de Estudios Sociales y Sociología Aplicada, 1997, vol. 106, p. 93147.

DE LA MADRID, Juan Carlos. Avilés, una historia de mil años. Avilés: Azucel, 1999.

DGASMF. Jornadas Técnicas Vivienda y Hábitat: Condicionantes de la exclusión social. Informe general. Madrid: Dirección General de Acción Social, del Menor y de la Familia, Ministerio de Trabajo y Asuntos Sociales, 1997.

FRESNO, José Manuel. Programa Municipal de Erradicación del Chabolismo en Avilés. Informe interno elaborado para la reunión Peer Review meeting Social Inclusion, celebrada en Avilés el 23 y 24 de Octubre de 2006, p. 20-37.

FUNDACIÓN SECRETARIADO GITANO. Gitanos y discriminación. Madrid: Fundación Secretariado General Gitano (Cuadernos Técnicos, vol. 20), 2001.

FUNDACIÓN SECRETARIADO GITANO. Intervención social en Avilés, en Memoria Territorial 2001, Asturias. Madrid: Fundación Secretariado General Gitano, 2002.

HERNANDEZ, Jesús y OLZA, Miguel. La exclusión social. Reflexión y acción desde el Trabajo Social. Pamplona: Eunate, 1998.

HIDALGO, Alberto. Reflexión ética sobre el racismo y la xenofobia. Madrid: Editorial Popular, 1993.

IRIS. La vivienda, un espacio para la convivencia intercultural. In Ponencias de las II Jornadas IRIS. Madrid: Instituto de Realojamiento e Integración Social, 2002.

LEAL, Jesús. Vivienda y sociedad. El análisis sociológico del problema de la vivienda, Revista Española de Investigación Sociológica (REIS), 1979, vol. 8, p. 89-102.
MARTINEZ, Santiago, VÁZQUEZ, Juan. A. et al. (coords.). La Erradicación del Chabolismo en Gijón. Análisis de su evolución y evaluación económica. Madrid: Civitas, 2000.

Ministerio de Trabajo y Asuntos Sociales. Tercer plan nacional de acción para la inclusión social del reino de España 2005-2006. Madrid: Ministerio de Trabajo y Asuntos Sociales. Capítulo 4, p.20.

MORALES, José Francisco y OLZA, Miguel (coords.). Psicología Social y Trabajo social. Madrid: McGraw-Hill Interamericana de España, 1999.

MORALES, José Francisco y YUBERO, Santiago. Del prejuicio al racismo: Perspectivas psicosociales. Cuenca: Ediciones Universidad de CastiIla-La Mancha, 1996.

PAJARES, Miguel. La inmigración en España. Barcelona: Icaria, 1998.

RODRÍGUEZ, Francesc. Trabajo social con gitanos. La vivienda. Ponencia en Jornadas sobre Intervención con la Comunidad Gitana de Madrid. Madrid: Fundación Secretariado Gitano, 1999.

Principado de Asturias. Otra forma de vivir. Revista El Gobierno del Principado de Asturias informa: noviembre 2001, p. 11.

RODRÍGUEZ, Isidro. La relevancia de la vivienda en los procesos de inclusión social con la Comunidad Gitana (Dossier Vivienda), Gitanos. Pensamiento y cultura, 2002, n 16, p. 20-24.

TAPADA, M. Teresa. Antropología, vivienda y realojamiento urbano: la necesidad de diseños arquitectónicos más flexibles y adaptados, en Gitanos. Pensamiento y cultura, 2002, $\mathrm{n}^{\circ} 16, \mathrm{p}$. 46-51.

VV.AA. I Jornadas sobre Intervención Social con Población Gitana. Avilés: Ayuntamiento de Avilés, 2002. 


\section{Fuentes en Prensa escrita}

DIARIO LA NUEVA ESPAÑA, 4/12/2001: "El plan antichabolismo se aplicará aunque genere crispación social", p. 6.

DIARIO LA VOZ DE AVILÉS, 2/12/2001: "Los grupos políticos coinciden en la necesidad de consenso", p. 3.

DIARIO LA VOZ DE AVILÉS, 18/06/02: "La nueva política de intervención para el colectivo defiende el alquiler de viviendas", publicado por M. R. López.

\section{Cita del artículo}

GUTIERREZ ÁLVAREZ, B. Avilés, por una convivencia intercultural. Proceso y resultados del Plan de Erradicación del chabolismo e integración social de los gitanos en Avilés 1989 - 2011. Hábitat y Sociedad, 2011, no 3, p. 133-150. <www.habitatysociedad.us.es>.

http://dx.doi.org/10.12795/HabitatySociedad.2011.i3.08 